\section{Commentary: Novel interventions in complex aortic disease: $A$ perfect storm to "B-SAFER"}

\author{
Giacomo Murana, MD, PhD, \\ Luca Di Marco, MD, PhD, and \\ Davide Pacini, MD, PhD
}

The frozen elephant trunk (FET) technique has been used in acute aortic dissection to stabilize the descending aorta at the stent level, promote re-expansion of the true lumen in the distal aorta, and ensure resolution of dynamic branch occlusion, restoring a normal flow in the visceral arteries. Since the introduction of this innovative procedure, various modifications to facilitate the management of the left subclavian artery (LSA) and reduce hypothermic circulatory arrest time have been attempted.

The branched single anastomosis frozen elephant trunk repair (B-SAFER) was introduced by the Cleveland Clinic in 2013 with the objective to simplify the FET procedure. Initially, they created a fenestration by resection of a portion of proximal stent graft to incorporate all the supra-aortic vessel; it was further modified in 2018 with a selective fenestration below the LSA and direct branch vessel stent grafting to avoid persistent false lumen perfusion. ${ }^{2}$ Unquestionably, every innovative technique should guarantee "simplification" but also "durability" to be reliable.

In this interesting issue of JTCVS Techniques, ${ }^{3}$ the authors presented 2 cases of distal aneurysmal expansion after a B-SAFER procedure secondary to persistent perfusion of the false lumen, which necessitated open repair. The first

\footnotetext{
From the Cardiac Surgery Department, S. Orsola Hospital, University of Bologna, Bologna, Italy.

Disclosures: The authors reported no conflicts of interest.

The Journal policy requires editors and reviewers to disclose conflicts of interest and to decline handling or reviewing manuscripts for which they may have a conflict of interest. The editors and reviewers of this article have no conflicts of interest.

Received for publication Oct 14, 2020; revisions received Oct 14, 2020; accepted for publication Oct 20, 2020; available ahead of print Oct 22, 2020.

Address for reprints: Davide Pacini, MD, PhD, Cardiac Surgery Department, S. Orsola Hospital, University of Bologna, Via Massarenti 9, 40138, Bologna, Italy (E-mail: davide.pacini@unibo.it or davide.pacini@aosp.bo.it).

JTCVS Techniques 2020;4:61-2

2666-2507

Copyright (C) 2020 The Authors. Published by Elsevier Inc. on behalf of The American Association for Thoracic Surgery. This is an open access article under the CC BY-NCND license (http://creativecommons.org/licenses/by-nc-nd/4.0/).

https://doi.org/10.1016/j.xjtc.2020.10.023
}

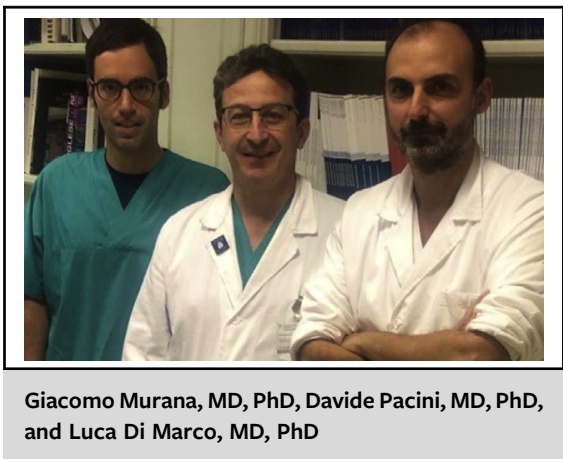

CENTRAL MESSAGE

Every novel intervention to treat complex aortic disease necessitates simplicity but also efficacy and durability to "B-SAFER."

patient had a persistent proximal flow from the dissected LSA into the false lumen, whereas the second had a proximal leak secondary to incomplete closure of the false lumen at the distal anastomosis to dissected zone 2 arch. In both situations, the new simplified FET operation had the primary limitation to leave untreated a re-entry tear in the distal arch, providing persistent retrograde flow into the false lumen. Likewise, stenting of the LSA is not always a guarantee of distal sealing and later the formation of endoleaks is common if the false lumen is not properly excluded from the aorta.

These drawbacks favor later distal aortic reinterventions, reducing the efficacy of FET that was born with the idea of treating not just the arch but also the descending thoracic aorta in a one-step procedure. The results of the literature clearly demonstrated the efficacy of FET in terms of false lumen thrombosis around the stent portion, true lumen expansion, and positive remodeling in downstream aortic segments in acute and chronic thoracic aortic dissections. ${ }^{4,5}$ This primary intention using the branched single-anastomosis FET repair is much mitigated in favor of an intraoperative simplification that might facilitate persistent blood flow into the false lumen. The use of such simplification might foster early complex reinterventions like in the Michigan experience, where both patients required an open TAAA repair 1 year after primary arch intervention. 
In conclusion, we might argue that B-SAFER remains a novel technique for complex aortic disease and it is critical to monitor its efficacy; however, every innovative treatment need not only "simplify" but also have "efficacy" and "durability," which is a perfect storm to "B-SAFER" for every new intervention.

\section{References}

1. Pacini D, Murana G, Di Marco L. Frozen elephant trunk technique: ready to get back to the future? J Thorac Cardiovasc Surg. 2018;156:e79-80.
2. Roselli EE, Idrees JJ, Bakaeen FG, Tong MZ, Soltesz EG, Mick S, et al. Evolution of simplified frozen elephant trunk repair for acute DeBakey type I dissection: midterm outcomes. Ann Thorac Surg. 2018;105:749-55.

3. Guo M, Naeem A, Yang B. The challenges of novel interventions in complex aortic disease. J Thorac Cardiovasc Surg Tech. 2020;4:57-60.

4. Leone A, Murana G, Coppola G, Berardi M, Botta L, Di Bartolomeo R, et al. Frozen elephant trunk-the Bologna experience. Ann Cardiothorac Surg. 2020; 9:220-2.

5. Iafrancesco M, Goebel N, Mascaro J, Franke UFW, Pacini D, Di Bartolomeo R, et al. Aortic diameter remodelling after the frozen elephant trunk technique in aortic dissection: results from an international multicentre registry. Eur J Cardiothorac Surg. 2017;52:310-8. 